
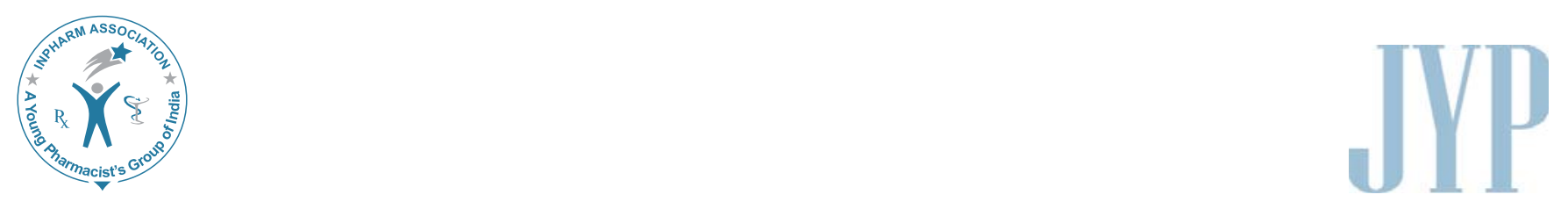

\title{
Evaluation and Quantification of Angiogenesis Activity of Terminalia Bellirica Roxb, by Mice Sponge Implantation Method
}

\author{
Vinoth Prabhu V ${ }^{1,2}$, Chidambaranathan $\mathbf{N}^{2}$, Gopal V 3 \\ ${ }^{1}$ Department of Pharmacology, Faculty of Pharmacy, PRIST University, Thanjavur, ${ }^{2}$ Department of \\ Pharmacology, KM College of Pharmacy, Madurai, Tamil Nadu, ${ }^{3}$ Department of Pharmacognosy, \\ College of Pharmacy, Mother Theresa Post Graduate and Research Institute of Health Sciences, \\ Puducherry, India
}

Address for correspondence: Prof. Vinoth Prabhu V; E-mail: vvinothprabhu@yahoo.com

\begin{abstract}
Angiogenesis represents an excellent therapeutic target for the treatment of cardiovascular diseases. It is a potent physiological process that underlies the natural manner in which our bodies respond to a diminution of blood supply to vital organs, namely the production of new collateral vessels to overcome the ischemic state. This present study is aimed to evaluate and quantify the Angiogenic potential of Terminalia bellirica Roxb, by in vivo mice sponge implantation assay. Here, gelatin sponge with or without Ethanolic extract of Terminalia bellirica leaf (EETB - $0.3 \mathrm{mg}$ and $0.5 \mathrm{mg}$, respectively) were subcutaneously injected into Swiss albino mice, and 14 days later, the implanted sponges was excised and histologically examined. The stained section showed that sponge containing EETB had produced more vessels in gels than sponges alone. The new vessels were abundantly filled with intact Red blood corpuscles (RBCs), which indicate the formation of a functional vasculature inside the sponges and blood circulation in newly formed vessels by angiogenesis which is induced by EETB. It also measured that the hemoglobin content inside the sponges: Whereas, hemoglobin in control was nearly $0.3 \mu \mathrm{g}$, EETB cases the hemoglobin quantity was markedly enhanced to about $17 \mu \mathrm{g}$. Taken together, it demonstrated that Ethanolic extract of Terminalia bellirica leaf exhibited a profound angiogenic activity in vivo. The phytochemical screening and qualitative instrumental analysis of EETB reveals the presence of proteins and Phytosterols. The promising angiogenic potential may be due to the presence of the above chemical constituents. Further study is required to define more precisely the molecular mechanisms by which Ethanolic extract of Terminalia bellirica leaf modulates endothelial cell function and gene expression, as well as the pathological relevance of these findings.
\end{abstract}

Key words: Angiogenic growth factors, sponge implantation assay, Terminalia bellirica, therapeutic angiogenesis

\begin{tabular}{|l|l|}
\hline \multicolumn{2}{|c|}{ Access this article online } \\
\hline Quick Response Code: & \\
\hline & Website: \\
\hline & www.jyoungpharm.in \\
& DOI: \\
\hline
\end{tabular}

\section{INTRODUCTION}

Neovascularization is the growth of new capillary blood vessels in the body, and is an important natural process for healing and reproduction. The body controls neovascularization by producing a precise balance of growth and inhibitory factors in healthy tissues. When this balance is disturbed, the 
result is either too much or too little angiogenesis. Abnormal blood vessel growth, either excessive or insufficient, is now recognized as a "common denominator" underlying many deadly and debilitating conditions, including cancer, skin diseases, age-related blindness, diabetic ulcers, cardiovascular disease, stroke, and many others. ${ }^{[1]}$

\section{Angiogenesis for cardiovascular diseases}

Angiogenesis represents an excellent therapeutic target for the treatment of cardiovascular diseases. It is a potent physiological process that underlies the natural manner in which our bodies respond to a diminution of blood supply to vital organs, namely the production of new collateral vessels to overcome the ischemic state. A large number of pre-clinical studies have been performed with protein, gene and cell-based therapies in animal models of cardiac ischemia as well as models of periphery artery diseases. Administration of a particular growth factor [Table 1] to stimulate angiogenesis in the affected tissues (or) organ, and the protein therapy with single protein agent was not a viable option to treat ischemic cardiovascular diseases. ${ }^{[2,3]}$

\section{Therapeutic angiogenesis}

Therapeutic angiogenesis is the method of stimulation of angiogenesis where it is required but lacking. This technique is used to replenish the blood supply to chronic wounds to speed healing and it prevents unnecessary amputations. New research suggests this approach can be also used to save limbs afflicted with poor circulation and even oxygen starved hearts. ${ }^{[4]}$ Therapeutic angiogenesis may even help to regenerate damaged (or) lost tissues in ways that were previously considered impossible, such as, with nerves and brain tissues. The modern clinical application of the principle of angiogenesis can be divided into two main areas: Antiangiogenesis therapies with which angiogenesis research began, and with Pro-angiogenic therapies. ${ }^{[5]}$ Antiangiogenic therapies are being employed to fight cancer and malignancies which require an abundance of oxygen and nutrients to proliferate. Pro-angiogenesis therapy is being explored as an option to treat cardiovascular diseases. One of the first applications of pro-angiogenic methods in humans was a German trial using fibroblast growth factor-1 (FGF-1) for the treatment of coronary artery diseases. Clinical research in therapeutic angiogenesis is ongoing for a variety of diseases like coronary artery diseases, peripheral arterial diseases and wound healing disorders. ${ }^{[6]}$ The pro-angiogenesis therapies can be differentiated into three categories, namely, i) protein therapy, ${ }^{[7]}$ ii) gene therapy ${ }^{[8]}$ and, iii) cell based therapy which involved the implantation of specific cell types. Other than
Table 1: Endogenous angiogenesis inducers

\begin{tabular}{ll}
\hline Type of angiogenesis inducer & Examples \\
\hline Heparin binding peptide growth & VEGF \\
factors & PlGF \\
& FGF-1, FGF-2 \\
& Pleiotrophin \\
& PDGF \\
Non-heparin binding peptide & TGF-a TGF-b \\
growth factors & EGF \\
Inflammatory mediators & IGF-I \\
& TNF-a \\
Enzymes & IL-8 IL-3 \\
& Prostaglandin E1, E2 \\
& PD-ECGF/TP \\
Hormones & COX-2 \\
& Angiogenin \\
Oligosaccharides & Oestrogens \\
& Proliferin \\
Hematopoietic factors & Hyaluronan \\
& Gangliosides \\
Cell adhesion molecules & Erythropoietin \\
Others & G-CSF \\
& GM-CSF \\
\hline
\end{tabular}

Where, VEGF: Vascular endothelial growth factor; PlGF: Placental growth factor; FGF-1, FGF-2: Fibroblast growth factors; PDGF: Platelet-derived growth factor; TGF-a: Transforming growth factor alpha; TGF-b: Transforming growth factor beta; EGF: Epidermal growth factor; IGF-I: Insulin-like growth factor I; TNF-a: Tumor necrosis factor alpha; IL-8: Interleukin - 8; IL-3: Interleukin - 3; PD-ECGF/ TP: Platelet-derived endothelial cell growth factor/thymidine phosphorylase; COX-2: Cyclooxygenase-2; G-CSF: Granulocyte colony-stimulating factor; GMCSF: Granulocyte macrophage colony-stimulating factor; VCAM-1: Vascular cell adhesion molecule-1; Ang-1: Angiopoietin 1

the above three therapies there are few therapies that have been used to induce angiogenesis. Hence, this study is aimed to find potent angiogenic herbal compounds. Terminalia bellirica has deep roots in Indian mythology as in Ayurveda. It is part of a compound rasayana preparation of three myrobalan fruits, known as Triphala (or trifla), which are important in both Indian and Tibetan traditional medicine. The name Vibheekaki indicates that regular use keeps a person healthy and free from diseases. It has been previously reported that the aqueous extract of fruits of Terminalia bellirica inhibit the Tumor Growth and Angiogenesis, and suggests different components have different activity, hence, fresh leafs of the Terminalia bellirica Roxb, belonging to the family Combretaceae, commonly known as Bellirica Myrobalan have been selected to evaluate its angiogenesis activity. ${ }^{[9]}$

\section{MATERIALS AND METHODS}

Phytochemical evaluation of plant extract

\section{Plant material}

The Fresh leaves of Terminalia bellirica were collected from wild area near to Mannargudi, Tiruvarur District, 
Tamil Nadu, India and the same were authenticated by Prof. Dr. G.S.V. Murthy-Botanical Survey of India (BSI), Coimbatore, India and a voucher specimen No: BSI/SRC/5/23/09-10/Tech-683 was allotted for Terminalia bellirica Roxb. [Figure 1]. The herbarium was deposited in our University laboratory for further reference.

\section{Preparation of ethanolic extract}

Freshly collected leaves of Terminalia bellirica were shade dried and made into small pieces. These pieces were again shade dried and pulverized to coarse powder and passed through the sieve No: 20, and retained on sieve No: 40. About $1 \mathrm{~kg}$ of the dry powder of leaves of Terminalia bellirica were placed in a thimble of the Soxhlet extraction apparatus attached to the mouth of a round bottomed flask containing $70 \%$ ethanol as an extractive solvent. Some boiling chips were added into the flask to avoid bumping during heating. Then the dry powder of leaves of Terminalia bellirica was extracted for 72 hours. The extract was concentrated by rotary vacuum evaporation, and the yield was $30 \% \mathrm{w} / \mathrm{w}$. The dried extract was the subjected to phytochemical screening. ${ }^{[10]}$

\section{Phytochemical screening}

Phytochemical screening of EETB was carried out using conventional protocol, ${ }^{[11]}$ for detecting the presence of different phytochemical active constitutes in the plant respectively, and the result is shown in Table 2.

\section{Qualitative instrumental analysis}

\section{Ultra violet and visible spectroscopy}

The absorption spectra of plant constituents can be measured in very dilute solution against a solvent blank using an automatic recording spectrophotometer. The ultraviolet (UV)-Visible spectroscopy of plant extract shows the peak at $255 \mathrm{~nm}$ which reveals the presence of proteins.

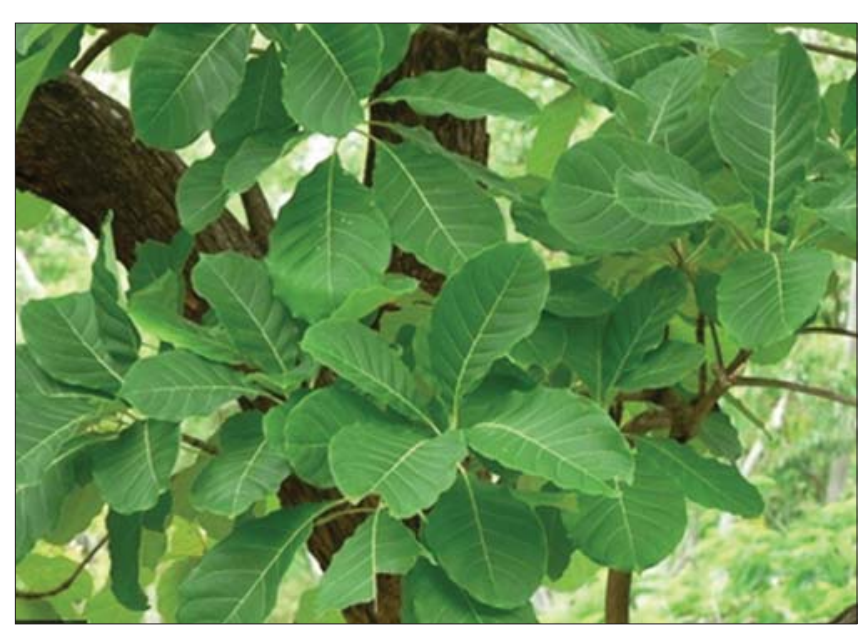

Figure 1: Leaves of Terminalia bellirica Roxb

\section{Infrared spectroscopy}

Infrared (IR) spectroscopy is the study of the reflected, absorbed or transmitted radiant energy in the region of electromagnetic spectrum ranging from wavelength of 0.8 to $500 \mathrm{~nm}$. Frequency expressed in wave numbers is a more commonly used measurement. It is usually divided into 3 regions near I.R. (1250 to $400 \mathrm{~cm}^{-1}$ ), mid I.R. (4000 to $400 \mathrm{~cm}^{-1}$ ) and far I.R. (400 to $20 \mathrm{~cm}^{-1}$ ). The powdered EETB was mixed with potassium bromide and a thin disc was prepared in anhydrous conditions. That disc was used for the measurement of I.R. spectra against the potassium bromide disc as reference. The Fourier transform infrared FT-IR-spectra of ethanolic extract of Terminalia bellirica leaf contains main absorption bands belonging to the valence vibrations corresponding to $\mathrm{OH}, \mathrm{C}=\mathrm{O}, \mathrm{C}-\mathrm{O}-\mathrm{C}$ groups to aromatic rings vibrations as well shows in Figure 2. Spectra examination reveals that the valence vibrations appears in the $2916 \mathrm{~cm}^{-1} \mathrm{~S}\left(\mathrm{CH}_{3} \mathrm{CH}_{2}\right)$ band, $2849 \mathrm{~cm}^{-1}(\mathrm{C}-\mathrm{H})$, $1713(\mathrm{C}=\mathrm{O}) \mathrm{cm}^{-1}, 1612 \mathrm{~cm}^{-1}$ (aromatic $\left.\mathrm{C}=\mathrm{O}\right), 1450 \mathrm{~cm}^{-1}$ (aromatic $\mathrm{C}=\mathrm{C}$ ring), 758 and $870 \mathrm{~cm}^{-1}$ (benzene ring), and may be due to the presence of Phytosterols. Also, it is found that the plant contains organic compounds like carbohydrates, cardiac glycosides, chlorophyll and lignins.

Evaluation and quantification of angiogenesis activity

\section{Animals}

Seven-week-old, specific pathogen-free Male Swiss albino mice weighing between $(32-34 \mathrm{gm})$ were purchased from Tamil Nadu Veterinary and Animal Sciences University, Chennai. They were housed in poly propylene cages ( 4 per cage), maintained in standard lab conditions at $25 \pm 2{ }^{\circ} \mathrm{C}, 10 \%$ humidity under a 12 hour light/dark cycle. They were fed with standard pellet diet and autoclaved tap water ad libitum. All procedures were performed with the animals under general

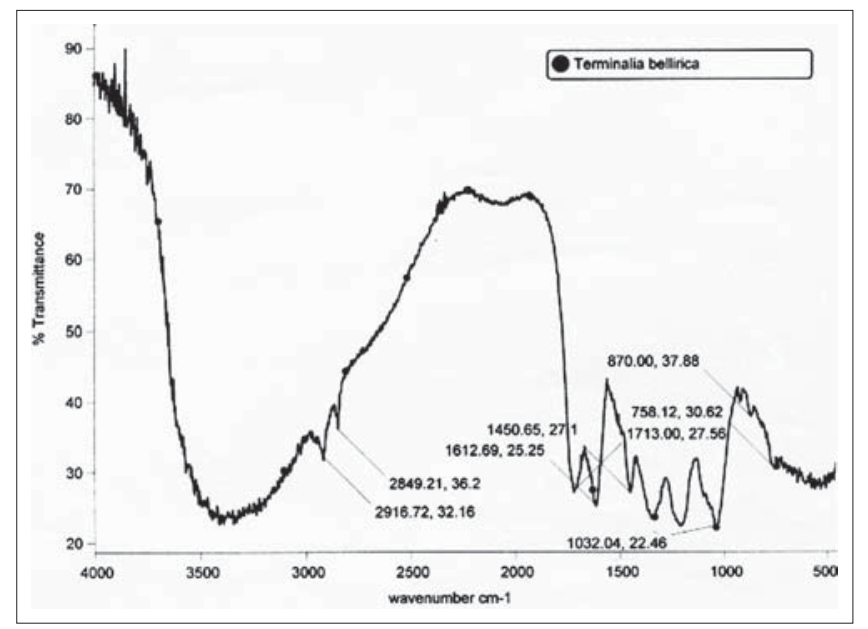

Figure 2: Fourier transform infrared (FT IR) spectra of ethanolic extract of Terminalia bellirica Roxb 
Table 2: Preliminary phytochemical screening of Terminalia bellirica Roxb. during the study

\begin{tabular}{llc}
\hline $\begin{array}{l}\text { Phytochemical } \\
\text { test }\end{array}$ & Test methods/reagents & Results \\
\hline Alkaloids & Mayer's & - \\
& Dragendroff's & - \\
Carbohydrates & Molisch's & - \\
and glycosides & Borntrager's & - \\
Cardiac & Legal's test & - \\
glycosides & Kellerkilliani test & - \\
Sugars & Fehling's test & - \\
& Benedict's test & - \\
Steroids & Liebermann's Burchard test & ++ \\
& Salkowski test & ++ \\
Tannins & Lead solution & - \\
Proteins & Aqueous gelatin solution & - \\
& Million's test & ++ \\
& Biuret test & ++ \\
Terpenoids & Ninhydrin test & ++ \\
Flavonoids & Xanthoprotein test & ++ \\
Anthocyanins & Noller's test & + \\
Quinones & Shinoda test & - \\
\hline indicates the presence & NaOH and conc. sulphuric acid & - \\
\hline
\end{tabular}

+ indicates the presence of phytochemical, ++ Indicates the presence of more quantity, - indicates the absence of phytochemical

anesthesia, that is, after intraperitoneal injection of sodium phenobarbitone $(30 \mathrm{mg} / \mathrm{kg})$. This study was approved by the Institutional Animal Ethical Committee (IAEC), Approval No: Pharm/12/2009-2010, and the all the animal experiments were performed according to the strict guidelines prescribed by Committee for the purpose of control and supervision on experiments on animals (CPCSEA).

\section{Acute toxicity studies}

Acute toxicity study was carried out on plant extract using female and male Swiss albino mice. The mice were fasted overnight and the weight of each mouse was recorded just before use. The extract was subjected for acute toxicity studies by following the OECD (Organization for Economical Co-operation and Development) guidelines No. 425. A group of 5 mice was administered the plant extract in graded doses of $0.25 \mathrm{~g} / \mathrm{kg}, 0.5 \mathrm{~g} / \mathrm{kg}, 1.0 \mathrm{~g} / \mathrm{kg}$, $1.5 \mathrm{~g} / \mathrm{kg}$, and $2.5 \mathrm{~g} / \mathrm{kg}$ mice. Mice were continuously observed for mortality and behavioral response for 48 hours. The dose selection was performed by taking $1 / 10^{\text {th }}$ of the lethal dose $\left(\mathrm{LD}_{5 \mathrm{O}}\right)$.

\section{Mice sponge implantation method}

The in vivo angiogenesis assay involving subcutaneous implantation of gelfoam sponges in mice was performed according to the method proposed by Vallera et al., and Mc Carty et al., Absorbable gel foam was cut $(5 \mathrm{~mm} \times 5 \mathrm{~mm} \times 5 \mathrm{~mm})$ and hydrated in sterile normal saline $(0.9 \%)$, and strengthened with sterile $0.4 \%$ agarose. ${ }^{[12]}$ Mice were divided into four groups and each group contains six animals. Mice were anaesthetized with sodium phenobarbitone $(30 \mathrm{mg} / \mathrm{kg}$, i.p.). The caudal region of the back was shaved and scrubbed with 95\% ethanol. An incision was made and a sponge wetted with sterile normal saline was inserted into each subcutaneous pocket created under the upper flap and pushed cephalad. This helps to decrease the incident of infection, and reduces the complications resulting from scar tissue forming. Immediately, the incision was sutured. The test and Pyruvic Acid which is used as standard substances were injected slowly through the skin into the sponges by using water as a vehicle. Animals were allowed to recover for 14 days. ${ }^{[13]}$

\section{Hemoglobin determination in implanted sponges}

On $14^{\text {th }}$ day animals were sacrificed with an overdose of sodium phenobarbitone, and the sponges were harvested from the mice, and were carefully stripped of any remaining peritoneum. The sponges were weighed by placing them into preweighed $1 \mathrm{ml}$ tube of double distilled $\mathrm{H}_{2} \mathrm{O}$ and homogenized for 5-10 minutes on ice. The samples were spun at 10,000 revolutions per minute $(\mathrm{rpm})$ on a micro centrifuge for 6 minutes, and the supernatants were collected for hemoglobin measurement. The supernatants were filtered through a $0.22-\mu \mathrm{m}$ filter, and fifty micro liters of supernatant were mixed with Drabkin's reagent, and allowed to sit at room temperature for 15-30 minutes). Hemoglobin $(\mathrm{Hb})$ in the samples was quantified calorimetrically at $540 \mathrm{~nm}$ in a spectrophotometer. The concentration of hemoglobin was calculated from a known amount of hemoglobin assayed in parallel. The results were expressed as $\mathrm{Hb} \mu \mathrm{g} / \mathrm{mg}$ wet sponges. ${ }^{[14]}$

\section{RESULTS}

Phytochemical screening and qualitative instrumental analysis

The phytochemical screening of plant extract revealed the presence of proteins, steroids and terpinoids. The UV-Visible spectroscopy of the plant extract gives maximum absorption at $255 \mathrm{~nm}$. The presence of proteins may have revealed the presence of $\mathrm{CH}_{3} \mathrm{CH}_{2},(\mathrm{C}-\mathrm{H}), \mathrm{C}=\mathrm{O}$, aromatic $\mathrm{C}=\mathrm{O}$, aromatic $\mathrm{C}=\mathrm{C}$ ring, and benzene ring in the IR-spectra of the plant extract.

Ethanolic extract of Terminalia bellirica leaf stimulates angiogenesis in vivo

The in vivo angiogenesis activity was then evaluated by the effect of EETB leaf on the ongoing angiogenesis process in the in vivo mice sponge implantation assay. Gelatin sponge with or without EETB leaf (0.3 mg 
and $0.5 \mathrm{mg}$, respectively) was subcutaneously injected into Swiss albino mice, and 14 days later, the implanted sponges in mice was excised and histological examined. Gelatin sponges alone were pale in their color indicating no or less blood vessel formation. In contrast, sponges mixed with EETB leaf appeared dark-red in color. As the sponges were treated with $0.5 \mathrm{mg}$ of EETB leaf, they contained too many large vessels to perform histological examination [Figure 3]. The stained section showed that sponge containing EETB leaf had produced more vessels in gels than sponges alone [Figure 4]. The new vessels were abundantly filled with intact RBCs, which indicated the formation of a functional vasculature inside the sponges, and blood circulation in newly formed vessels by angiogenesis, induced by EETB leaf. It also measured the hemoglobin content inside the sponges [Table 3] to

Table 3: Angiogenesis activity induced by ethanolic extract of Terminalia bellirica leaf in mice sponge implantation method

\begin{tabular}{llc}
\hline Group & Treatment & $\begin{array}{c}\text { Hemoglobin present } \\
\text { hemoglobin } \\
\mu \mathrm{g} / \mathrm{mg} \text { wet sponge } \\
\text { (mean } \pm \text { standard } \\
\text { error of Mean) }\end{array}$ \\
\hline Control & Gel foam & $0.317 \pm 0.031$ \\
Standard & Gel foam+P.A. $(500 \mu \mathrm{g})$ & $22.667 \pm 0.667^{* * *}$ \\
Test A & Gel foam+T.B. $(300 \mu \mathrm{g})$ & $10.667 \pm 0.882^{* * *}$ \\
Test B & Gel foam+T.B. $(500 \mu \mathrm{g})$ & $17.667 \pm 0.882^{* * *}$ \\
\hline
\end{tabular}

All the results were expressed as mean \pm SEM and $* * * P<0.001, * * P<0.005$ and

$* P<0.05$ considered as a significant where (n.s) as not significant

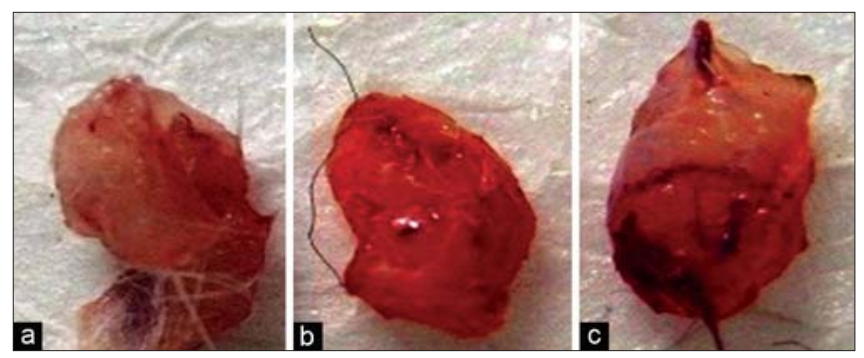

Figure 3: Angiogenesis induced by Terminalia bellirica in in-vivo mice sponge implantation assay. a) The sponge alone. b) Sponge with Pyruvic acid $(500 \mu \mathrm{g})$. c) Sponge with Terminalia bellirica extract $(500 \mu \mathrm{g})$

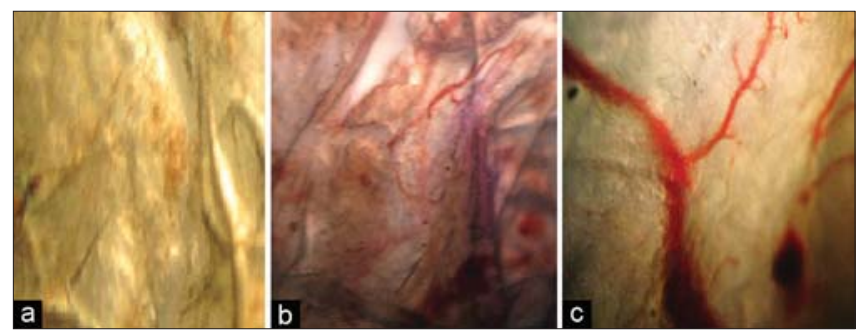

Figure 4: (a) The sponge without pro-angiogenic agent does not show blood vessel supply. However, the sponge with Pyruvic acid $500 \mu \mathrm{g}$ (b) shows angiogenesis and the sponge with Terminalia bellirica leaf extract $(500 \mu \mathrm{g})$ shows (c) many blood vessels appeared quantify the angiogenesis induced by EETB leaf. Whereas hemoglobin in control was nearly $0.3 \mu \mathrm{g}$, the hemoglobin content was markedly enhanced by EETB to about $17 \mu \mathrm{g}$. Taken together, It is proved that EETB leaf exhibited a profound angiogenic activity in vivo.

\section{Statistical analysis}

All the values are expressed as Mean $\pm \operatorname{SEM}(n=6)$ and $* * * P<0.001$ considered as significant when compared to control. Statistical comparisons between control and treated groups were carried out using one-way analysis of variances (ANOVA) and differences between groups assessed using Dunnet's $t$ test. All statistical analysis was done by using Graph Pad Prism 5 software.

\section{DISCUSSION}

Therapeutic angiogenesis is the method of stimulation of angiogenesis where it is required but lacking. This technique is used to replenish the blood supply to chronic wounds to speed healing and it prevents unnecessary amputations. New research also suggests that this approach can be also used to save limbs afflicted with poor circulation and even oxygen starved hearts. Therapeutic angiogenesis may even help to regenerate damaged (or) lost tissues in ways that were previous considered impossible such as with nerves and brain tissues. Developing novel angiogenic agents that have a well-developing mechanism of action is most important in angiogenesis field. Three types of therapies were developed up to now: Namely, protein therapy; gene transfer technology; and, stem cell transplantation which were most costly and have side effects. In this direction, the plants are being actively explored as a source of new molecules that can induces angiogenesis. In the present study, we have clearly elucidated the angiogenic activity of EETB leaf by performing in vivo angiogenesis assays. In mice sponge implantation assay, EETB highly elevated the formation of neovessels in implanted sponges and these newly synthesized vessels participated actively in the circulating of blood cells in mice [Figure 3]. Taken together, the observations in the present study suggest that EETB leaf exhibits strong angiogenic actions, and also may have the potential to be a useful modulator of the large number of serious diseases characterized by deregulated angiogenesis.

\section{CONCLUSION}

The preliminary phytochemical screening of the EETB has showed the presence of proteins, sugars, 
phytosterols, Terpinoids and tannins. The acute toxicity study was carried out and a dose level of $2000 \mathrm{mg} / \mathrm{kg}$ body weight orally in mice was considered to be safe for pharmacological treatment. The results of this study support the development and use of Terminalia bellirica as a well-tolerated, safe and less cost angiogenic agent with potential angiogenic therapy. The hemoglobin present in the extract treated group was increased when compare to the control group implanted sponges. The histopathology of the implanted sponges shows the presence of the blood vessels in the extract treated groups. Thus, from the foregoing findings it was observed that leaf of Terminalia bellirica is a promising angiogenic agent, and this angiogenic activity may be due to the presence of proteins. This is the first report which is not previously said, as well as not yet it is reported that plant proteins inhibit angiogenesis. Further study is required to define more precisely the molecular mechanisms by which proteins of EETB leaf modulate endothelial cell function and gene expression, as well as the pathological relevance of these findings.

\section{ACKNOWLEDGEMENT}

The authors wish to express their gratitude towards the Hon. Chancellor, PRIST University, Thanjavur and Hon. Chairman, K.M. College of Pharmacy, Madurai for providing the necessary facilities to carry out this research work.

\section{REFERENCES}

1. Carmeliet P. Angiogenesis in health and diseases. Nat Med 2003;9:32-7.

2. Yin-Shan NG, Patricia Amore AD. Therapeutic angiogenesis for cardiovascular disease. Curr Control Trials Cardiovasc Med 2001;2:278-85.

3. Fedak PW, Verma SS, Weisel RD, Mickle DA, Ren-Ke Li. Angiogenesis: Protein, Gene, or Cell Therapy. Heart Surg Forum 2001;4:301-4.

4. Wadhwa S. Therapeutic myocardial angiogenesis: A ray of hope for patients unsuitable for CABG/PTCA. J Indian Acad Clin Med 2000;1:252-5.

5. Folkman J. Therapeutic angiogenesis in ischemic limbs. Circulation 1998;97:1108-10.

6. Pantely GA, Porter JM. Therapeutic angiogenesis: Time for the next phase. J Am Coll Cardiol 2000;36:1245-7.

7. Azrin M. Angiogenesis, protein and gene delivery. Br Med Bull 2001;59:211-25.

8. Zuckerbraun BS, Tzeng E. Vascular gene therapy. Arch Surg 2002;137:854-61.

9. Gilani AH, Khan AU, Ali T, Ajmal S. Mechanisms underlying the antispasmodic and bronchodilatory properties of Terminalia bellerica fruit. J Ethnopharmacol 2008;116:528-38.

10. Molla MT, Alam MT, UIslam MA. Physic-chemical and nutritional studies of Terminalia Belerica Roxb. seeed oil and seed kernel. J Biosci 2007;15:117-26.

11. Kokate CK, Purohit AP, Gokhale SB. Pharmacognosy. $13^{\text {th }}$ ed. Pune: Nirali Prakashan; 1999. p. 92-3.

12. Mathur R, Gupta SK, Singh N, Mathur S, Kochupillai V, Velpandian T. Evaluation of the effect of Withania somnifera root extracts on cell cycle and angiogenesis. J Ethnopharmacol 2006;105:336-41.

13. Lee MS, Moon EJ, Lee SW, Kim MS, Kim KW, Kim YJ. Angiogenic activity of pyruvic acid in in vivo and in vtro angiogenesis models. Cancer Res 2001;61:3290-3.

14. Wang D, Carretero OA, Yang XY, Rhaleb NE, Liu YH, Liao TD, et al. $\mathrm{N}$-acetyl-seryl-aspartyl-lysyl-proline stimulates angiogenesis in vtro and in vivo. Am J Physiol Heart Circ Physiol 2004;287:2099-105.

How to cite this article: Prabhu VV, Chidambaranathan N, Gopal V. Evaluation and quantification of angiogenesis activity of Terminalia bellirica roxb, by mice sponge implantation method. J Young Pharmacists 2012;4:22-7.

Source of Support: Nil, Conflict of Interest: None declared.

\section{Author Help: Reference checking facility}

The manuscript system (www.journalonweb.com) allows the authors to check and verify the accuracy and style of references. The tool checks the references with PubMed as per a predefined style. Authors are encouraged to use this facility, before submitting articles to the journal.

- The style as well as bibliographic elements should be $100 \%$ accurate, to help get the references verified from the system. Even a single spelling error or addition of issue number/month of publication will lead to an error when verifying the reference.

- Example of a correct style Sheahan P, O'leary G, Lee G, Fitzgibbon J. Cystic cervical metastases: Incidence and diagnosis using fine needle aspiration biopsy. Otolaryngol Head Neck Surg 2002;127:294-8.

- Only the references from journals indexed in PubMed will be checked.

- $\quad$ Enter each reference in new line, without a serial number.

- Add up to a maximum of 15 references at a time.

- If the reference is correct for its bibliographic elements and punctuations, it will be shown as CORRECT and a link to the correct article in PubMed will be given.

- If any of the bibliographic elements are missing, incorrect or extra (such as issue number), it will be shown as INCORRECT and link to possible articles in PubMed will be given. 